\title{
The ovulatory response to human chorionic gonadotropin administration on day 4 post timed artificial insemination improved fertility in repeat breeder cows
}

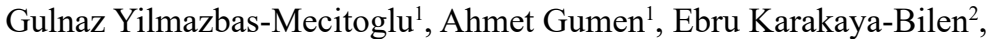 \\ Abdulkadir Keskin ${ }^{1}$, Baris Guner ${ }^{3}$, Rabia Cakircali ${ }^{1}$ \\ ${ }^{1}$ University of Bursa Uludag, Faculty of Veterinary Medicine, Department of Obstetrics and Gynecology, \\ Bursa, Turkey \\ ${ }^{2}$ University of Siirt, Faculty of Veterinary Medicine, Department of Obstetrics and Gynecology, Siirt, Turkey \\ ${ }^{3}$ University of Balıkesir, Faculty of Veterinary Medicine, Department of Obstetrics and Gynecology, Balıkesir, Turkey
}

Received June 11, 2020

Accepted February 24, 2021

\begin{abstract}
This study focused on determining the success of inducing endogenous progesterone source (by formation of accessory corpus luteum) by human chorionic gonadotropin (hCG) administration on day 4 post timed artificial insemination (TAI) and on evaluating the effect of the day of hCG administration (day 4 or 5 post TAI) on pregnancy rates in repeat breeder cows according to their responses to hCG administrations. Non-pregnant cyclic lactating Holstein dairy cows with more than three services despite no clinical reproductive abnormalities were enrolled in the study. All cows $(n=192)$ received the Ovsynch protocol $(\mathrm{GnRH}-7 \mathrm{~d}-\mathrm{PGF}-56 \mathrm{~h}-\mathrm{GnRH}-16 / 18 \mathrm{~h}-\mathrm{TAI})$ and hCG administration (1500 IU, i.m.) was performed in group hCG4 $(n=64)$ on day 4 and in group hCG5 $(\mathrm{n}=68)$ on day 5 post TAI. The control group $(\mathrm{CON}, \mathrm{n}=60)$ did not receive any hCG treatment. The responses (ovulation rate) to hCG $(\sim 64 \%)$ were similar on days 4 and 5 post TAI. Pregnancy per AI (P/AI) at 31 days was similar among the groups $(48.3 \%$ in $\mathrm{CON}$, $48.4 \%$ in hCG4, and $42.6 \%$ in hCG5). Regardless of the day of the treatment (hCG4 + hCG5), the cows had an ovulatory response to hCG $(54.1 \%)$, and a greater P/AI $(P=0.007)$ at 31 days than those without a response (29.8\%). The administration of hCG on either day 4 or 5 post TAI did not increase overall pregnancy rates, however, the ovulatory response to the post TAI hCG administration on day 4 improved fertility in repeat breeder cows. Further studies are needed with a larger number of animals to reveal this potentiallly beneficial effect.
\end{abstract}

Cattle, repeat breeding, $h C G$, post TAI

Repeat breeder (RB) cows are generally defined as cows that have no pregnancy after more than three services despite normal cyclicity and healthy genital tracts (Zemjanis 1980). Repeat breeding causes important financial loss on dairy farms because of increased calving intervals, culling rates, and insemination costs. Since there are multiple factors that correlate with repeat breeding in cows, the specific reasons remain speculative (Gustafsson and Emanuelson 2002). Most prominent aetiological factors include oestrus detection errors, infections, and hormonal disturbances leading to embryonic mortalities (Gustafsson and Emanuelson 2002; Opsomer 2014). Hormonal disturbances such as delayed progesterone increases (Shelton et al. 1990; Bage et al. 2002; Moss et al. 2002; Kendall et al. 2009) and decreased total concentrations of progesterone after ovulation (Shelton et al. 1990; Bage et al. 2002) may induce embryonic mortalities which occur mostly 6 to 8 days after timed artificial insemination (TAI) in RB cows (Shelton et al. 1990). Since progesterone plays a critical role in embryonic development and continuation of pregnancy, several studies have focused on either exogenous or endogenous progesterone supplementation during the post-TAI period to increase the pregnancy rate (Tefera et al. 2001; Mann et al. 2006; Khoramian et al. 2011; Wiltbank et al. 2011). Endogenous progesterone can be stimulated by induction of ovulation of the dominant follicle generated

Address for correspondence:

Gulnaz Yilmazbas-Mecitoglu

Department of Obstetrics and Gynecology

Faculty of Veterinary Medicine, University of Bursa Uludag

Gorukle Campus, 16059, Bursa, Turkey

Phone: +902242940827

E-mail: gulnazy@uludag.edu.tr

http://actavet.vfu.cz/ 
from the first follicular wave after TAI using either gonadotropin releasing hormone $(\mathrm{GnRH})$ or human chorionic gonadotropin (hCG) administration to produce an accessory corpus luteum (CL) (Helmer and Britt 1986; Santos et al. 2001; Stevenson et al. 2007; Beltran and Vasconcelos 2008). It is reported that administration of hCG on day 5 post TAI increases progesterone levels (Thatcher et al. 2001; Beltran and Vasconcelos 2008), embryo development (Nascimento et al. 2013) and pregnancy rates (Thatcher et al. 2001; Beltran and Vasconcelos 2008; Shabankareh et al. 2010; Khoramian et al. 2011; Nascimento et al. 2013). In similar studies focused on RB cows, a beneficial effect of hCG administration on day 5 post TAI on pregnancy rates was reported (Kendall et al. 2009; Khoramian et al. 2011; Pandey et al. 2016). Thus, supporting pregnancy by inducing endogenous progesterone source as early as possible may result in improved fertility. Likewise, studies evaluating hCG administration on day 4 post TAI are limited in both lactating dairy cows (Tefera et al. 2001; Fischer-Tenhagen et al. 2010) and RB (Alnimer and Shamoun 2015) cows. Thus, more knowledge is needed about the effect of earlier administration of hCG on day 4 post TAI on dairy cows' fertility. With this aim, this study focused to determine the success of inducing endogenous progesterone source by hCG administration one day 4 post TAI and also to evaluate the effect of the day of hCG administration (day 4 or 5 post TAI) on pregnancy rates in RB cows according to their responses to hCG administrations.

Table 1. Feed ingredients for the total mixed ration.

\begin{tabular}{lc}
\hline Ingredient & Amount \% of DM \\
\hline Corn silage (32\% DM) & 31.18 \\
Alfaalfa hay (16\% protein) & 11.61 \\
Wheat straw & 1.85 \\
Triticale silage (34\% DM) & 5.12 \\
Wet orange pulp & 3.93 \\
Wet corn gluten feed (42\% DM) & 9.35 \\
Sodium bicarbonate & 0.64 \\
Toxin binder & 0.04 \\
Yeast (Saccharomyces cerevisiae) & 0.02 \\
Magnesium oxide & 0.20 \\
Dry corn gluten feed & 0.54 \\
Corn gluten (65\% protein) & 0.79 \\
Hydrogenised rumen bypass fat & 1.57 \\
Dairy Min/Vit complex & 0.04 \\
Cotton seed meal (38\% protein) & 8.32 \\
Crushed corn grain & 2.29 \\
Distillers' dried grains & 5.45 \\
Soy bean meal (48\% protein) & 1.90 \\
Barley & 1.16 \\
Corn & 0.63 \\
Sunflower seed meal (38\% protein) & 1.00 \\
Molasses (sugar beat) & 0.84 \\
Calcium carbonate & 0.48 \\
Salt & 0.32 \\
Bakery byproducts & 4.43 \\
Wheat middlings & 6.31 \\
\hline & \\
\hline &
\end{tabular}

DM - dry matter

\section{Materials and Methods}

\section{Animals}

Cyclic lactating Holstein dairy cows that had been subjected to more than three services with no clinical reproductive abnormalities (RB cows, $n=214$ ) from a commercial dairy farm were enrolled in the present study for over a year's period. The cows were kept in free-stall dairy barns and fed a total mixed ration (Table 1, NRC 2001) with access to water ad libitum. Data regarding the milk yield and reproductive health of each cow were obtained from the management program of the dairy farm (Alpro 2000, DeLaval, Tumba, Sweden). Cows with a history of metritis were not included in the study. The average milk yield of each cow was noted from 7 days before to after AI. All cows were scored at the beginning of the study using the 5-point body condition scoring (BCS) system (Ferguson et al. 1994). The treatment groups were formed equally according to BCS, milk production, days in milk (DIM), service and lactation numbers (Table 2). This research was approved by the Lalahan Livestock Central Research Institute Animal Care Committee (No: 2009 / 27).

\section{Treatment groups}

All cows $(\mathrm{n}=214)$ received the Ovsynch protocol, which includes GnRH administration (Buserelin acetate, i.m., $10 \mu \mathrm{g}$, Oviren $^{\circledR}$, Topkim, İstanbul, Turkey) and prostaglandin $\mathrm{F}_{2 \alpha}\left(\mathrm{PGF}_{2 \alpha}\right)$ administration (Dinoprost, 25 mg, i.m., Enzaprost ${ }^{20}$, Ceva, İstanbul, Turkey) 7 days later. The second GnRH administration was performed $56 \mathrm{~h}$ after $\mathrm{PGF}_{2 \alpha}$ administration, and all cows were inseminated at a fixed time (TAI) $16 \mathrm{~h}$ to 18 $h$ after the second GnRH injection. Twenty-two out of 214 cows that had early ovulation (lack of a follicle at TAI) or no ovulation (no CL at $4 \mathrm{~d}$ after TAI) were defined as non-synchronized cows and were excluded from the study. After TAI, all synchronized cows 
Table 2. General results, ovarian responses to the treatments and pregnancy rates of repeat breeder cows.

\begin{tabular}{|c|c|c|c|c|}
\hline Item & $\mathrm{CON}$ & hCG4 & hCG5 & $P$ value \\
\hline $\mathrm{BCS}$ & $2.87 \pm 0.05$ & $2.87 \pm 0.05$ & $2.81 \pm 0.04$ & 0.58 \\
\hline Milk production (kg/day) & $31.6 \pm 0.79$ & $30.2 \pm 0.76$ & $31.4 \pm 0.74$ & 0.38 \\
\hline DIM & $228.8 \pm 6.7$ & $237.6 \pm 6.6$ & $232.0 \pm 6.3$ & 0.64 \\
\hline Service number & $3.36 \pm 0.09$ & $3.48 \pm 0.08$ & $3.42 \pm 0.08$ & 0.61 \\
\hline Lactation number & $2.20 \pm 0.16$ & $2.36 \pm 0.15$ & $2.32 \pm 0.15$ & 0.76 \\
\hline Follicle size at TAI, mm & $15.49 \pm 0.32$ & $15.26 \pm 0.31$ & $15.94 \pm 0.30$ & 0.28 \\
\hline Follicle size at $4 \mathrm{~d}$ post TAI, mm & $12.28 \pm 0.54$ & $11.63 \pm 0.40$ & $11.52 \pm 0.40$ & 0.51 \\
\hline Ovulation to first $\mathrm{GnRH}, \%$ (n/total) & $70.0 \%(42 / 60)$ & $68.8 \%(44 / 64)$ & $77.9 \%(53 / 68)$ & 0.44 \\
\hline Ovulation to hCG, $\%$ (n/total) & - & $64.1 \%(41 / 64)$ & $64.7 \%(44 / 68)$ & 0.94 \\
\hline \multicolumn{5}{|l|}{ Pregnancy/AI, \% (n/total) } \\
\hline At $31 \mathrm{~d}$ & $48.3 \%(29 / 60)$ & $48.4 \%(31 / 64)$ & $42.6 \%(29 / 68)$ & 0.74 \\
\hline At $62 \mathrm{~d}$ & $45.0 \%(27 / 60)$ & $42.2 \%(27 / 64)$ & $39.7 \%(27 / 68)$ & 0.64 \\
\hline Pregnancy loss & $6.9 \%(2 / 29)$ & $12.9 \%(4 / 31)$ & $6.9 \%(2 / 29)$ & 0.44 \\
\hline
\end{tabular}

hCG4 and hCG5 included repeat breeder cows treated with hCG administration on day 4 or 5 post TAI, respectively. CON included untreated repeat breeder cows.

DIM - days in milk; BCS - body condition score; TAI - timed artificial insemination; AI - artificial insemination

$(n=192)$ were randomly assigned to three groups. The cows in the hCG4 group $(n=64)$ received hCG $(1500 \mathrm{IU}$, i.m., Chorulon ${ }^{\circledR}$, MSD, İstanbul, Turkey) on day 4 post TAI, the cows in the hCG5 group $(\mathrm{n}=68)$ received 1500 IU hCG i.m. on day 5 post TAI, and the cows in the control $(\mathrm{CON})$ group $(n=60)$ did not receive any treatment post TAI.

\section{Ultrasonographic examinations}

Evaluations of ovaries were performed via transrectal ultrasonography with a $7.5 \mathrm{MHz}$ transducer (Honda HS 2000, Honda ${ }^{\circledR}$, Tokyo, Japan). Cows that had at least one CL on the ovaries were included in the study, and the size of the largest follicle in the ovaries was also measured. Follicular diameter was determined by using the mean diameters in two directions at the right angle of the largest frozen image of the follicle. In addition, ultrasonographic examinations were performed on the day of $\mathrm{PGF}_{2 \alpha}$ administration (to determine ovulation after the first GnRH injection), on the day of TAI (to determine the size of the ovulatory follicle), on the day of hCG administration ( $4 \mathrm{~d}$ after TAI, to determine ovulation after the second GnRH injection and to measure the follicle size) and 7 days after hCG administration (to determine ovulation after hCG administration). Ovulations in response to the GnRH and hCG treatments were verified by the disappearance of the dominant follicle and the appearance of a new CL. Pregnancy checks were performed 31 and 62 days after TAI by ultrasonography.

\section{Statistical analysis}

Statistical analyses were performed using SAS (version 9.4, SAS Inst. Inc., Cary, NC). The data were evaluated with PROC LOGISTIC, PROC GLM and PROC FREQ analyses in the SAS program. The statistical model included the effects of treatments, parity, DIM, BCS, service number, average milk production, responses to the first and second GnRH and hCG administrations, and follicle sizes at the time of TAI and at 4 days post TAI. To analyse the differences between groups in milk production, DIM, BCS, and follicle size at the time of TAI and 4 days post TAI, the PROC GLM program was used. Chi-square results were obtained using the PROC FREQ procedure for independent tests to analyse the differences in the GnRH administration response and pregnancy/ artificial insemination (P/AI, 31 and 62 days) between the groups. The effects of covariant factors on P/AI (31 and 62 days) were determined with the LOGISTIC procedure. For all statistical analyses, $P$ values $<0.05$ were accepted as significant while those $<0.10$ were considered to indicate a tendency towards significance.

\section{Results}

\section{General results}

The response to first GnRH administration in Ovsynch (72.4\%) and the maximum follicle size at the time of TAI $(\sim 15.5 \mathrm{~mm})$ were found to be similar $(P>0.05)$ among the groups (Table 2). 
The follicle diameter at day 4 post TAI was not different $(P=0.51)$ among the groups $(12.28 \pm 0.54 \mathrm{~mm}$ in CON, $11.63 \pm 0.40 \mathrm{~mm}$ in hCG4, and $11.52 \pm 0.40 \mathrm{~mm}$ in hCG5). The ovulatory responses to hCG administration were similar $(P=0.94)$ between the cows that received hCG on day $4(64.1 \%)$ vs. on day $5(64.7 \%)$ post TAI (Table 2$)$. Pregnancy per $\mathrm{AI}(\mathrm{P} / \mathrm{AI})$ at 31 days was similar $(P=0.74)$ among the groups $(48.3 \%$ in $\mathrm{CON}, 48.4 \%$ in hCG4, and $42.6 \%$ in hCG5; Table 2$)$. Pregnancy/AI at 62 days was also similar $(P=0.64)$ among the groups (45.0\% in CON, $42.2 \%$ in hCG4, and $39.7 \%$ in hCG5). Pregnancy loss was similar $(P=0.44)$ among the groups $(6.9 \%$ in $\mathrm{CON}, 12.9 \%$ in hCG4, $6.9 \%$ in hCG5). According to the logistic regression, BCS, DIM, milk production, service number, and parity did not have effects on $\mathrm{P} / \mathrm{AI}(P>0.05)$.

\section{Effect of response to hCG administration on $\mathrm{P} / \mathrm{AI}$}

When hCG-treated cows were evaluated, regardless of the day of the treatment, the cows that were responsive to hCG $(54.1 \%, 46 / 85)$ had a greater $(P=0.007) \mathrm{P} / \mathrm{AI}$ at 31 days than the cows that were not responsive $(29.8 \%, 14 / 47)$. Additionally, P/AI at 62 days was higher $(P=0.008)$ in the cows that were responsive to hCG $(49.4 \%, 42 / 85)$ than in the cows that were not responsive $(25.5 \%, 12 / 47)$. However, pregnancy loss was similar $(P>0.05)$ between the cows that were responsive to hCG $(8.7 \%, 4 / 46)$ and the cows that were not responsive $(14.3 \%, 2 / 14)$.

The pregnancy/AI values at 31 and 62 days were not different $(P=0.43, P=0.92)$ either in responsive cows between the hCG4 and hCG5 groups $(58.5 \%$ vs. $50.0 \%)$ or in nonresponsive cows between the hCG4 and hCG5 groups (30.4\% vs. 29.2\%; Table 3 ).

Pregnancy per AI at 31 days was higher $(P=0.03)$ in the cows that were responsive $(58.5 \%)$ than in those that were not responsive to hCG administration $(30.4 \%)$ in the hCG4 group, while $\mathrm{P} / \mathrm{AI}$ tended to be higher $(P=0.09)$ in responsive cows $(50.0 \%)$ than in nonresponsive cows $(29.2 \%)$ in the hCG5 group (Table 3 ). Pregnancy per AI at 62 days was higher $(P=0.01)$ in the responsive cows $(53.7 \%)$ than in the nonresponsive cows $(21.7 \%)$ in the hCG4 group, but there was no difference between these cows in the hCG5 group (Table 3). Embryonic loss was not different between the groups (Table 3).

Table 3. Results of pregnancy/AI at 31 and $62 \mathrm{~d}$ pregnancy in cows according to their response to hCG administration between the hCG groups.

\begin{tabular}{lccccccccc}
\hline & \multicolumn{3}{c}{ 31-d pregnancy } & \multicolumn{3}{c}{ 62-d pregnancy } & \multicolumn{3}{c}{ Pregnancy loss } \\
& $\mathrm{hCG}(+)$ & $\mathrm{hCG}(-)$ & $P$ value & $\mathrm{hCG}(+)$ & $\mathrm{hCG}(-)$ & $P$ value & $\mathrm{hCG}(+)$ & $\mathrm{hCG}(-)$ & $P$ value \\
\hline $\mathrm{hCG} 4$ & 58.5 & 30.4 & 0.03 & 53.7 & 21.7 & 0.01 & 8.3 & 28.6 & 0.16 \\
$\%(\mathrm{n} /$ total $)$ & $(24 / 41)$ & $(7 / 23)$ & $(22 / 41)$ & $(5 / 23)$ & $(2 / 24)$ & $(2 / 7)$ & & & \\
$\mathrm{hCG}$ & 50.0 & 29.2 & 0.09 & 45.5 & 29.2 & 0.19 & 9.0 & 0 & 0.41 \\
$\%($ n/total $)$ & $(22 / 44)$ & $(7 / 24)$ & & $(20 / 44)$ & $(7 / 24)$ & & $(2 / 22)$ & $(0 / 7)$ & \\
$P$ value & 0.43 & 0.92 & & 0.45 & 0.56 & & 0.93 & 0.13 & \\
\hline
\end{tabular}

hCG4 and hCG5 included repeat breeder cows treated with hCG administration on day 4 or 5 post TAI, respectively.

$\mathrm{AI}$ - artificial insemination; TAI - timed artificial insemination

\section{Discussion}

The success of inducing endogenous progesterone source which is determined by ovulatory response to post-TAI administration of hCG on days 5-7 is accepted as adequate, with response rates of 60 to $100 \%$ in lactating dairy cows (Santos et al. 2001; Nascimento et al. 2013; Torres et al. 2013), but the response to hCG on day 4 post TAI has not yet been documented. In the present study, the response to hCG administration on 
day $4(64.1 \%)$ was similar to that on day $5(64.7 \%)$ and was within the ranges observed in other studies (Santos et al. 2001; Nascimento et al. 2013; Torres et al. 2013). Likewise, the follicle sizes (11.56 $\mathrm{mm}$ on average) measured on day 4 in all cows seemed appropriate for induction of ovulation by hCG (Sartori et al. 2001). Thus, administration of hCG on day 4 post TAI is similarly effective in inducing ovulation and generating an accessory CL on day 5 which is commonly used.

Administration of hCG either 4 or 5 days after TAI to RB cows did not increase pregnancy rates or decrease embryonic loss compared to the control regimen in the present study. Previous studies including small numbers of RB cows (Khoramian et al. 2011; Pandey et al. 2016) have reported a beneficial effect of hCG treatment on day 5 post TAI. However, Kendall et al. (2009) reported no improvement in fertility after hCG treatment in RB cows, similar to our findings. While no effect of hCG on overall PR was found in this study, it has been reported that hCG treated cows with progesterone concentrations between 2 to $4 \mathrm{ng} / \mathrm{ml}$ at 5 days post TAI have higher pregnancy rates than control cows (Kendall et al. 2009). Similarly, in the present study, higher pregnancy rates at both 31 and 62 days post TAI were observed in cows responsive to hCG administration than in nonresponsive cows, regardless of the day of hCG administration. Since these responsive cows with accessory CL could be assumed advantageous in terms of progesterone levels compared to nonresponsive cows, post TAI hCG treatment either on day 4 or 5 may be accepted as beneficial in responsive RB cows in this study.

Embryonic loss was not different among the groups, similar to the results of Tefera et al. (2001) who reported that promoting luteal function post AI had no effect on embryonic mortality in lactating dairy cows. However, our results conflict with the other studies focused on $\mathrm{hCG}$ administration on day $4 / 5$ post $\mathrm{AI}$ that reported beneficial effects in both RB cows (Alnimer and Shamoun 2015) and lactating dairy cows (for only summer months, Fischer-Tenhagen et al. 2010).

The pregnancy rates on days 31 and 62 were higher in cows that had an ovulatory response to hCG administration on day 4 compared to cows not responsive to the treatment. Such a difference was not observed between responsive and nonresponsive cows in group hCG5. The increased pregnancy rates in responsive cows in group hCG4 may have been due to one day earlier administration of hCG which is consistent with the previous studies that reported that advancing hCG administration from day 5 to day 4 post AI may improve embryo development and hence fertility due to earlier progesterone increase (Mann et al. 2006; Nascimento et al. 2013). The earlier administration of hCG may have also had the effect of improving the size and luteal activity of the primary CL (Rizos et al. 2012), besides its primary effect of inducing accessory CL, since ovulatory responses to hCG were similar between the groups in the present study.

In conclusion, although administration of hCG either on day 4 or 5 post TAI did not increase overall pregnancy rates compared to untreated RB cows that served as control, the ovulatory response to the post TAI hCG administrations improved fertility regardless of the day of hCG administration. Furthermore, hCG administration on day 4 post TAI appeared to be more beneficial than that on day 5, not only exhibiting similar efficiency in inducing the formation of an accessory $\mathrm{CL}$ as the endogenous progesterone source, but also producing better pregnancy rates in the cows that had an ovulatory response. Further studies are needed with a larger number of RB cows to explore this potential beneficial effect.

\section{Acknowledgement}

Dr. Gulnaz Yilmazbas-Mecitoglu was supported by the TUBITAK-BIDEB 2219 International Postdoctoral Research Fellowship Program. This study was also supported by University of Bursa Uludag, Scientific Research Projects Council, Grant No. KUAP(V)-2019/1. 


\section{References}

Alnimer MA, Shamoun AI 2015: Treatment with hCG 4 or 6 days after TAI to improve pregnancy outcomes in repeat-breeding dairy cows. Anim Reprod Sci 157: 63-70

Bage R, Gustafsson H, Larsson B, Forsberg M, Rodríguez-Martínez H 2002: Repeat breeding in dairy heifers: follicular dynamics and estrous cycle characteristics in relation to sexual hormone patterns. Theriogenology 57: $2257-2269$

Beltran MP, Vasconcelos JLM 2008: Conception rate in Holstein cows treated with GnRH or hCG on the fifth day post artificial insemination during summer. Arq Bras Med Vet Zootec 60: 580-586

Ferguson JD, Galligan DT, Thomsen N 1994: Principal descriptors of body condition score in Holstein cows. J Dairy Sci 77: 2695-2703

Fischer-Tenhagen C, Thiele G, Heuwieser W, Tenhagen BA 2010: Efficacy of a treatment with hCG 4 days after AI to reduce pregnancy losses in lactating dairy cows after synchronized ovulation. Reprod Domest Anim 45: $468-472$

Gustafsson H, Emanuelson U 2002: Characterisation of the repeat breeding syndrome in Swedish dairy cattle. Acta Vet Scand 43: 115-125

Helmer SD, Britt JH 1986: Fertility of dairy cattle treated with human chorionic gonadotrophin (hCG) to stimulate progesterone secretion. Theriogenology: 26: 683-695

Kendall NR, Flint APF, Mann GE 2009: Incidence and treatment of inadequate postovulatory progesterone concentrations in repeat breeder cows. Vet J 181: 158-162

Khoramian B, Farzaneh N, Talebkhan Garoussi M, Mohri M 2011: Comparison of the effects of gonadotropinreleasing hormone, human chorionic gonadotropin or progesterone on pregnancy per artificial insemination in repeat-breeder dairy cows. Res Vet Sci 90: 312-315

Mann GE, Fray MD, Lamming GE 2006: Effects of time of progesterone supplementation on embryo development and interferon- $\tau$ production in the cow. Vet $\mathrm{J}$ 171: $500-503$

Moss N, Lean LJ, Reid SWJ, Hodgson DR 2002: Risk factors for repeat breeder syndrome in New South Wales dairy cattle. Prev Vet Med 54: 91-103

Nascimento AB, Souza AH, Guenther JN, Costa FPD, Sartori R, Wiltbank MC 2013: Effects of treatment with human chorionic gonadotropin or intravaginal progesterone-releasing device after AI on circulating progesterone concentrations in lactating dairy cows. Reprod Fertil Dev 25: 818-824

National Research Council (NRC) 2001: Nutrient requirements of dairy cattle. $7^{\text {th }}$ rev, Natl Acad Press, Washington, DC, USA

Opsomer G 2014: New insights in the causes of and treatments for repeat breeder cows. Reprod Domest Anim 49: 39 (Abstract)

Pandey N, Gupta H, Prasad S, Sheetal S 2016: Plasma progesterone profile and conception rate following exogenous supplementation of gonadotropin-releasing hormone, human chorionic gonadotropin, and progesterone releasing intra-vaginal device in repeat-breeder crossbred cows. Vet World 9: 559-562

Rizos D, Scully S, Kelly AK, Ealy AD, Moros R, Duffy P, Al Naib A, Forde N, Lonergan P 2012: Effects of human chorionic gonadotrophin administration on day 5 after oestrus on corpus luteum characteristics, circulating progesterone and conceptus elongation in cattle. Reprod Fertil Dev 24: 472-481

Santos JEP, Thatcher WW, Pool L, Overton MW 2001: Effect of human chorionic gonadotropin on luteal function and reproductive performance of high producing lactating Holstein dairy cows. J Animal Sci 79: 2881-2894

Sartori R, Fricke PM, Ferreira JCP, Ginther OJ, Wiltbank MC 2001: Follicular deviation and acquisition of ovulatory capacity in bovine follicles. Biol Reprod 65: 1403-1409

Shabankareh HK, Zandi M, Ganjali M 2010: First service pregnancy rates following post-AI use of hCG in Ovsynch and Heatsynch programmes in lactating dairy cows. Reprod Domest Anim 45: 711-716

Shelton K, Gayerie de Abreu MF, Hunter MG, Parkinson TJ, Lamming GE 1990: Luteal inadequacy during the early luteal phase of subfertile cows. J Reprod Fertil 90: 1-10

Stevenson JS, Portaluppi MA, Tenhouse DE, Lloyd A, Eborn DR, Kacuba S, DeJarnette JM 2007: Interventions after artificial insemination: conception rates, pregnancy survival, and ovarian responses to gonadotropinreleasing hormone, human chorionic gonadotropin, and progesterone. J Dairy Sci 90: 331-340

Tefera M, Chaffaux S, Thibier M, Humblot P 2001: A short note: lack of effect of post-AI, hCG or GnRH treatment on embryonic mortality in dairy cattle. Livest Prod Sci 71: 277-281

Thatcher WW, Guzeloglu A, Mattos R, Binelli M, Hansen TR, Ptu JK 2001: Uterine-conceptus interactions and reproductive failure in cattle. Theriogenology 56: $1435-1450$

Torres A, Chagas e Silva J, Deloche MC, Humblot P, Horta AE, Lopes Da Costa L 2013: Secondary corpora lutea induced by HCG treatment enhanced demi-embryo survival in lactating high-yielding dairy cows. Reprod Domest Anim 48: 643-650

Wiltbank MC, Souza AH, Carvalho PD, Bender RW, Nascimento AB 2011: Improving fertility to timed artificial insemination by manipulation of circulating progesterone concentrations in lactating dairy cattle. Reprod Fertil Dev 24: $238-243$

Zemjanis R 1980: "Repeat Breeding" or conception failure in cattle. In: Morrow DA (Ed.): Current Therapy in Theriogenology. W.B. Saunders, Philadelphia, PA, USA, pp. 205-221 